\title{
Analysis of Scarp Profiles: Evaluation of Errors in Morphologic Dating
}

\author{
JEAN-PHILIPPE AVOUAC ${ }^{1}$
}

\author{
Laboratoire de Tectonique, Institut de Physique du Globe de Paris
}

\begin{abstract}
Morphologic analysis of scarp degradation can be used quantitatively to determine relative ages of different scarps formed in cohesionless materials, under the same climatic conditions. Scarps of tectonic origin as well as wavecut or rivercut terraces can be treated as topographic impulses that are attenuated by surface erosional processes. This morphological evolution can be modelled as the convolution of the initial shape with erosion (or degradation) function whose width increases with time. Such modelling applies well to scarps less than $10 \mathrm{~m}$ high, formed in unconsolidated fanglomerates. To a good approximation, the degradation function is Gaussian with a variance measuring the degree of rounding of the initial shape. This geometric parameter can be called the degradation coefficient. A synthetic experiment shows that the degradation coefficient can be obtained by least squares fitting of profiles levelled perpendicular to the scarp. Gravitational collapse of the free face is accounted for by assuming initial scarp slopes at the angle of repose of the cohesionless materials $\left(30^{\circ}-35^{\circ}\right)$. Uncertainties in the measured profiles result in an uncertainty in degradation coefficient that can be evaluated graphically. Because the degradation coefficient is sensitive to the regional slope and to three-dimensional processes (gullying, loess accumulation, stream incision. etc.), a reliable and accurate determination of degradation coefficient requires several long profiles across the same scarp. The linear diffusion model of scarp degradation is a Gaussian model in which the degradation coefficient is proportional to numerical age. In that case, absolute dating requires only determination of the propotionality constant, called the mass diffusivity constant. For Holocene scarps a few meters high, in loose alluvium under arid climatic conditions, mass diffusivity constants generally range between 1 and $6 \mathrm{~m}^{2} / \mathrm{kyr}$. Morphologic analysis is a reliable method to compare ages of different scarps in a given area, and it can provide approximate absolute ages of Holocene scarplike landforms.
\end{abstract}

\section{INTRODUCTION}

The geomorphic expression of an active fault is usually characterized by offsets of features such as rivers, ridges, terrace levels and terrace risers, or moraines or simply of the sloping topographic surface. The kinematics of an active fault can be constrained by measurements of such offset features, combined with dating. Measurement of offsets is a relatively simple and easy task, especially with modern digital geodetic instruments. Dating of the morphology is less straightforward. In arid and semiarid regions, organic material (such as peat or charcoal) is rare, which makes ${ }^{14} \mathrm{C}$ dating a painstaking endeavour. Based on the use of other cosmogenic isotopes (such as ${ }^{36} \mathrm{Cl},{ }^{10} \mathrm{Be}$ or ${ }^{26} \mathrm{Al}$ ), of thermoluminescence or of desert varnish development, new techniques may soon allow easier accurate dating. Morphologic dating is an alternate method that derives from the simple observation that the shape of a scarp is a function of its age [Wallace, 1977]. This approach assumes a model of scarp degradation which, providing that the rate of degradation is known, allows determination of the age of a single-event fault scarp, of an alluvial terrace riser or of a shoreline to be determined from the measurement of its geometric characteristics.

In this paper, we first discuss the diffusion model of scarp degradation and certain significant results from previous studies. We then present a more general erosion model and show how scarp degradation can be modelled as a Gaussian smoothing of the shape Now at Laboratoire de Détection et de Géophysique, CEA, Bruyères-le-
Châtel, France.

Copyright 1993 by the American Geophysical Union. of the scarp. A normalized procedure is derived to evaluate quantitatively the state of degradation of a scarp using topographic profiles. The sensitivity of this method to measurement errors and ill-constrained parameters is then tested.

\section{DIFFUSION MODEL OF SCARP DEGRADATION}

The typical morphologic evolution of a scarp was first described by Wallace [1977]. Several surface processes, controlled by climatic and geological factors, contribute to that evolution. In the cohesionless materials that make most of the surface deposits in which such evolution has been studied, scarp degradation starts with a gravity-driven phase of slope decline leading to the destruction of the free face and to the formation of a debris wedge at the angle of repose of the alluvium or soil, generally between $30^{\circ}$ and $35^{\circ}$ [e.g., Carson and Kirkby, 1972; Pierce and Coleman, 1986]. Following this phase of usually short duration (10 to 100 years), slower erosional processes, such as wash slope, rain splash, or solifluxion, become dominant. Such processes round off the angularities at the base and crest of the scarp. Wallace [1977] suggested that either the maximum scarp slope or the curvature of the crest are agedependent geometric characteristics and may be used as quantitative age indicators.

Bucknam and Anderson [1979] proposed a scarp height versus slope angle representation that relates slope decline to age and suggests scaling relationships between contemporaneous scarps. A mathematical two-dimensional model of degradation of scarps formed in cohesionless materials was later developed on the basis of an idealized diffusion like erosional process [Nash, 1980a, b]. In this model the rate of downslope transfer of surface debris, $S$, is assumed to be proportional to the local slope,

$$
S=k \frac{\partial U}{\partial x}
$$


where $U$ is the vertical elevation, $x$ is the horizontal distance, positive upslope (Figure 1 ), and $k$ is the mass diffusivity.

The conservation of mass in cross section yields the condition

$$
\frac{\partial U}{\partial t}=-\frac{\partial S}{\partial x}
$$

Assuming $k$ to be constant with time, the elevation of the profile is a function of horizontal distance $x$ and of time $t$, giving the linear diffusion equation:

$$
\frac{\partial U}{\partial t}=k \frac{\partial^{2} U}{\partial x^{2}}
$$

Assuming a simple initial shape, such as shown in Figure 1, synthetic profiles derived from the diffusion equation are very similar to real profiles of shorelines or fault scarps in cohesionless materials [Nash, 1980a, 1984; Hanks et al, 1984; Hanks and Wallace, 1985]. In particular, the diffusion model roughly accounts for the scaling relationships between coeval scarps of different heights.

Different dating techniques have been derived from the diffusion model. In most, the maximum scarp slope $\operatorname{tg} \theta$ is considered to be
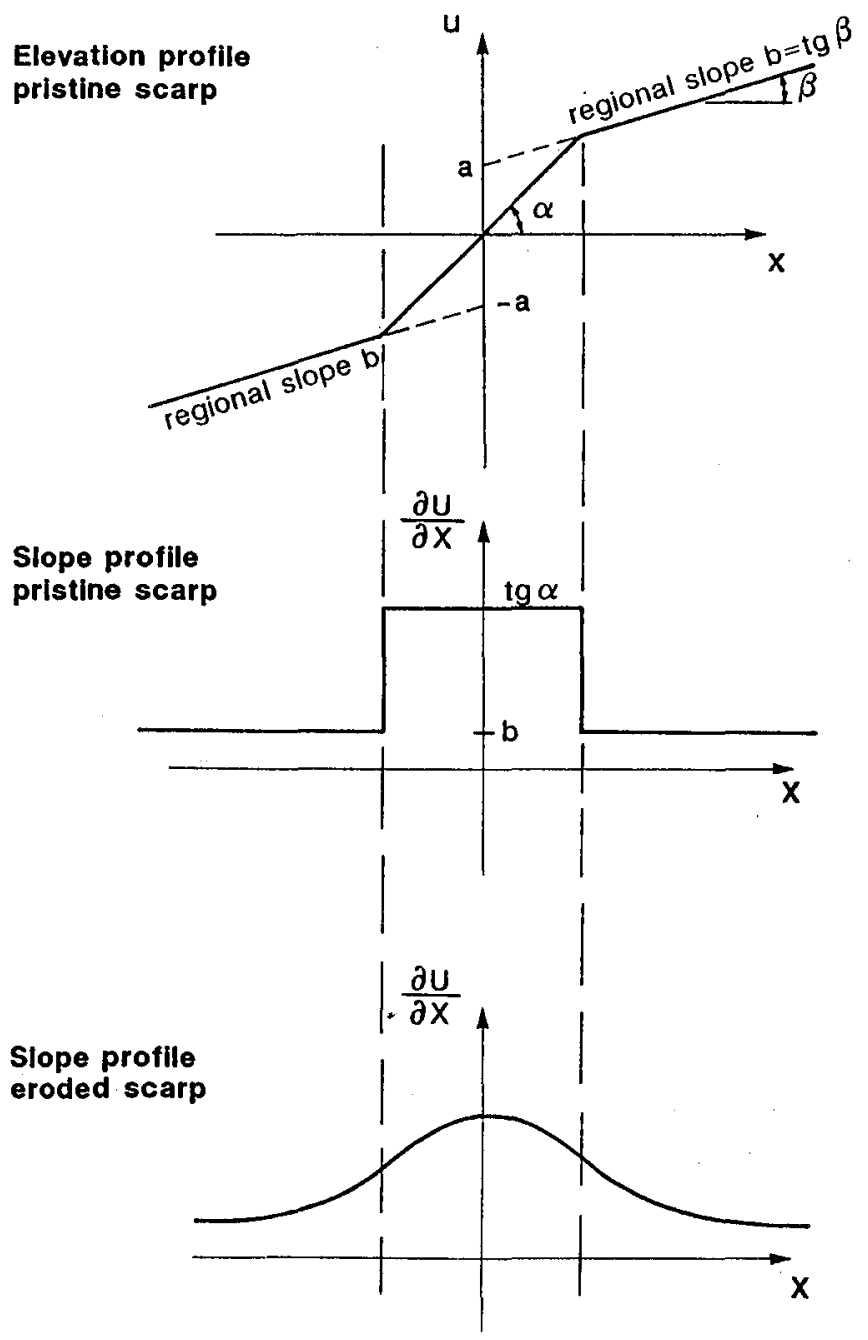

Fig.1. Simplest approximation of fresh scarp geometry is finite initial slope scarp. It represents scarp offseting a planar regional topography once gravitational collapse of free face has stopped. $\alpha$ is angle of repose of materials; $b$ is regional slope, and $a$ is half offset. Slope profiles for fresh and eroded scarps are shown underncath. the key geometric parameter. The linear diffusion equation with constant mass diffusivity yields

$$
\begin{aligned}
& \text { For } \alpha=90^{\circ}, \quad \operatorname{tg} \theta=\frac{a}{\sqrt{\pi \tau}}+b, \\
& \text { For } \alpha \neq 90^{\circ}, \operatorname{tg} \theta=(\operatorname{tg} \alpha-b) \operatorname{erf}\left[\frac{a}{2 \sqrt{\pi \tau}(\operatorname{tg} \alpha-b)}\right]+b,
\end{aligned}
$$

where $\operatorname{tg} \alpha$ is the initial scarp slope ( $\alpha$ being the angle of repose of the materials), $2 a$ the scarp offset, and $b$ is the regional slope (Figure 1).

The product of the numerical age by the mass diffusivity constant $k t$ can be estimated directly from one scarp, using equation (5) and measurements of the regional slope, half offset, and maximum scarp slope (see, for example, Nash [1980a] or Pierce and Colman [1986]). If a set of profiles presumed to be of the same age and of various heights is available, Hanks et al. [1984] suggest plotting the reduced scarp slope $\operatorname{tg} \theta-b$ as a function of the scarp half offset. The plot should display an error function (5) or, for old enough scarps (for which the initial scarp slope can be neglected), be a straight line (4). The plot thus permits to estimate $k t$ and to test the validity of the diffusion model from the scaling laws predicted by the diffusion equation for scarps of the same age and of different heights.

Another attempt at developing a dating method based on the linear diffusion model was introduced by Andrews and Hanks [1985]. They suggested computation of the second moment of scarp slope:

$$
M_{2}=\frac{1}{2} \int_{-\infty}^{+\infty} x^{2}\left(\frac{\partial U}{\partial x}-b\right) d x,
$$

where the origin of coordinates is fixed at the point of the offset midheight (Figure 1).

According to the diffusion equation (3), equation (6) leads to a direct estimate of the diffusion age,

$$
k t=\frac{M_{2}}{2 a}-\frac{1}{6}\left[\frac{a}{\operatorname{tg} \alpha-b}\right]^{2} .
$$

Here the geometric parameters derived from a scarp profile are the half offset, the regional slope, and $M_{2}$, instead of the maximum scarp slope. The diffusion age thus takes into account the width of the scarp slope distribution and the global shape of the scarp profile, and not only the maximum scarp-slope. The evaluation of $M_{2}$, however, is very sensitive to farfield topographic irregularities and often biased by a "lever arm effect": small irregularities in the slope distribution, far from the scarp midheight point, have a great weight in the calculation of $M_{2}$. This is a numerical artefact since those irregularities are not related to the degradation of the scarp and should be filtered out.

These various dating techniques based on the diffusion model yield, as a final answer, the product $k t$. Calibration (i.e., the determination of the apparent mass diffusivity $k$ ) is thus required to obtain numerical ages. This has been the object of several studies conducted in the western North America. Unfortunately, it seems that for scarps formed in similar cohesionless materials and under a similar semiarid climatic environment, the mass diffusivity constants can vary by a factor of ten, between 1 and $11 \mathrm{~m}^{2} / \mathrm{kyr}$ (Table 1). Pierce and Colman [1986], for example, have carried out a study of a set of terrace risers of known ages in Idaho to explore the dependency of the mass diffusivity constant on climatic, geologic and even geometric factors. That study showed a conspicuous dependency of mass diffusivity on scarp orientation as 
TABLE 1. Mass Diffusivity Constants

\begin{tabular}{lccccc}
\hline Region & Nature of Scarp & $\begin{array}{c}\text { Scarp Height } \\
\mathbf{m}\end{array}$ & $\begin{array}{c}\text { Approximate } \\
\text { Age. kyr }\end{array}$ & $\begin{array}{c}\text { Mass Diffusivity } \\
\mathbf{m}^{2} / \mathbf{k y r}\end{array}$ & Reference \\
\hline California & sea cliffs & $\approx 40$ & $100-370$ & 11 & Hanks et al. [1984] \\
Utah & shorelines & $1-12$ & $14-15$ & 1.1 & Hanks et al. $[1984]$ \\
Nevada & shorelines & $1-5$ & $12-14$ & 1.1 & Hanks and Wallace [1985] \\
Idaho & terrace edges & $2-5$ & 15 & $0.3-1.6$ & Pierce and Colman [1986] \\
Idaho & terrace edges & $10-15$ & 15 & $0.7-5.2$ & Pierce and Colman [1986] \\
Idaho & terrace edges & $\approx 20$ & 15 & $1.2-7$ & Nash [1984] \\
Monitana & terrace edges & $1.5-8$ & 7.5 & $2 \pm 0.4$ & Tapponnier et al. [1990] \\
Gansu & fault scarps & $\approx 0.8$ & 2 & $3.3 \pm 1.7$ & Avouac et al. [this issue] \\
Dzuungaria & terrace edges & $5.5-12$ & 10 & $5.5 \pm 2$ & J.P. Avouac and G. Peltżer (submitted manuscript 1992) \\
Tarim basin & terrace edges & $2.5-10$ & 10 & $3.5 \pm 1.2$ & \\
\hline
\end{tabular}

well as a clear positive correlation between apparent mass diffusivity and scarp height (see also Colman and Watson [1983] and Hanks et al. [1984]): $k$ is seen to vary between 0.7 and 5.2 $\mathrm{m}^{2} / \mathrm{kyr}$ for scarps about $10-15 \mathrm{~m}$ high, and between 0.3 and 1.6 $\mathrm{m}^{2} / \mathrm{kyr}$ for scarps about $5 \mathrm{~m}$ high. It has been proposed that nondiffusive processes could account for the positive correlation of apparent mass diffusivity with scarp height. More sophisticated nonlinear diffusion models have been developed where the transport law is not simply proportional to slope [Andrews and Hanks, 1985; Andrews and Bucknam, 1987]. Andrews and Bucknam [1987], for instance, introduced a cubic term in the debris transport law:

$$
S \alpha \frac{\partial U}{\partial x}\left[1+\left(\frac{\partial U}{\partial x}\right)^{2}\right)
$$

and derived synthetic profiles which fit real scarp profiles beiter than do synthetic profiles derived from the linear diffusion model.

Early expectations of dating of scarps using diffusion models have thus been mitigated by difficulties in calibrating rates of degradation and the variability of such rates. Nevertheless, it is clear that quantitative estimates of the degree of degradation of scarps formed in similar cohesionless materials, of similar heights and orientation yield easily and rapidly retrievable information on their relative ages: Compared to other models, the linear diffusion model presents the advantage of simplicity. Although it fails to model scarp degradation completely, it remains a useful means to characterize scarp morphology in term of only three parameters (half offset $a$; regional slope $b$; diffusion age $k t$ ); one of which, the diffusion age depends on age.

One reason why morphologic dating has not enjoyed wide success may be that the methods by which scarp degradation is estimated are quite sensitive to unrecognized sources of errors. Small variations in the measurement of the regional slope, maximum scarp-slope angles or scarp height, for instance, can result in large variations of the inferred value of the diffusion age $k t$ [Hanks and Andrews, 1989]. Because of gullying, of small fans deposited at the base of scarps, of trapped eolian sediments, or of other factors, a scarp profile may also display irregularities that, unless identified and corrected for, may lead to greatly erroneous diffusion ages. Large variations in diffusion ages may even result from different levelling techniques or site selections [Mayer, 1984].

At this stage, it seems that what morphologic dating requires most is a reliable and simple technique of evaluation of the degree of degradation of a scarp that includes a systematic test of validity and estimate of error. We noted that the plot of the scarp slope distribution, together with the scarp profile, often highlights potential problems. Such a systematic inspection of measured profiles, and the rejection of those whose shape departs from that predicted by the diffusion model, is efficient to reduce scatter and erroneous determination of $k t$. Taken together, the above remarks have led us to propose a simple analysis of scarp morphology by least squares fitting of synthetic profiles to measured profiles. In addition to being less sensitive to the various sources of error, this approach does not require inferences on the detailed physics of erosion processes that are often poorly constrained.

\section{EROSION AS A GAUSSIAN SMOOTHING}

Without attempting to take into account all the physical and chemical factors that may contribute to the erosion of a scarp, we propose below a simple mathematical description of the overall process of scarp degradation. Whatever its origin, a scarp is a local offset of the regional topography. Once a regular debris slope has formed, erosion acts to smooth the discontinuity. If we regard the slope as a distribution function, a scarp can be treated as a topographical impulse that becomes subsequently attenuated by geomorphic degradation processes (Figure 2). The cross-strike width of this attenuated impulse will depend both on its height and state of degradation. If we consider only surface processes that locally conserve mass, excluding stream and eolian erosion or deposition processes, a mathematical expression can be formulated in terms of convolution. The scarp profile at time $t$ is the result of the convolution of the scarp profile at time $t_{0}\left(t_{0}<t\right)$ with an erosion function, $E\left(x,\left[t_{0}, t\right]\right)$, which simulates the smoothing action of erosion during the time period $t-t_{0}$. This is expressed by

$$
U(x, t)=E\left(x,\left[t_{0}, t\right]\right) * U\left(x, t_{0}\right),
$$

where the asterisk denotes the convolution operator.

The model is illustrated in Figure 2 where $R(x, t)$ is the regional topography and $S(x, t)$ the topography of the scarp. After some time, small topographic wavelengths, on the order of the scarp horizontal extent, are smoothed by erosion, whereas longer wavelengths remain almost unaffected. The evolution of the regional topography is thus negligible compared to that of the scarp. In particular a rectilinear profile (i.e. with uniform slope) is unaffected by smoothing. This corresponds to the idea that linear segments are just transport slopes.

The erosion function $E$ can be determined from typical examples of scarp profiles such as rivercut terraces or fault scarps formed on nearly planar regional topography. If we approximate the initial shape of the scarp by a steplike function, the topographic profile across the scarp at $t_{0}$ is described by 
Time to
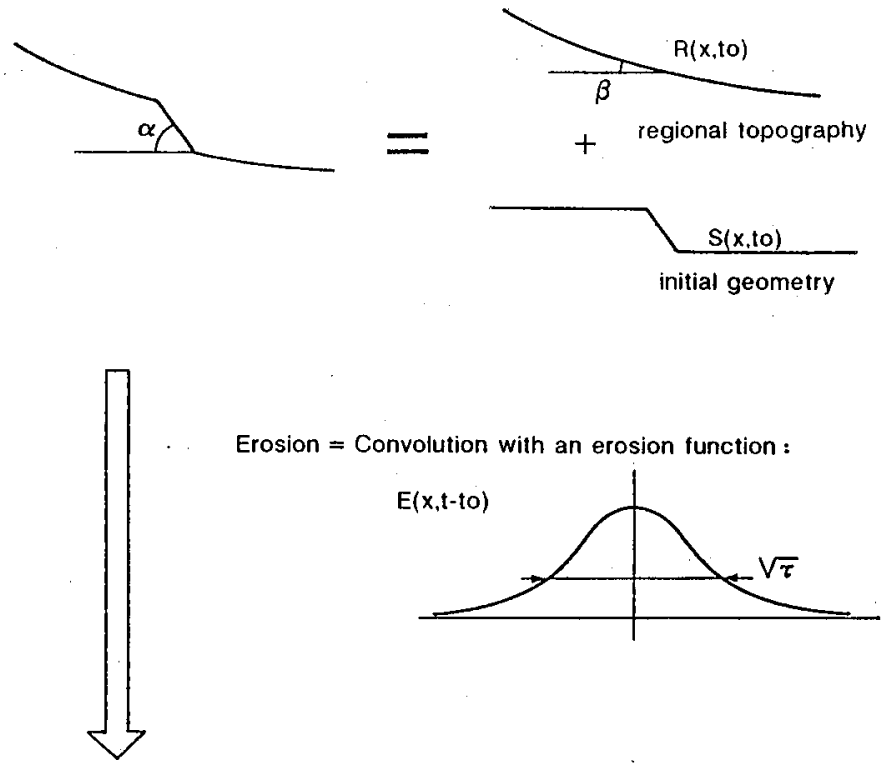

Time $\mathbf{t}$

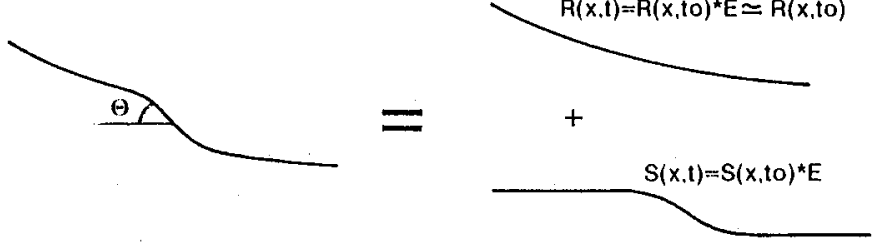

Fig. 2. Surfacic erosional processes acting on scarp formed in cohesionless materials result in smoothing of scarp profile. Mathematically, such processes may be viewed as convolution of initial shape with an erosion function $E$ whose width increases with age.

$$
U\left(x, t_{0}\right)=2 a H(x)+b x
$$

where $t_{0}$ is the time at which the scarp has formed, $a$ is the half scarp offset, $b$ is the regional slope, and $H$ denotes the Heavyside function defined by

$$
\begin{gathered}
H(x)=-\frac{1}{2}, \text { for } x<0, \\
H(x)=\frac{1}{2}, \text { for } x>0 .
\end{gathered}
$$

According to (9), at time $t>t_{0}$, erosion will lead to a smoother scarp shape given by,

$$
U(x, t)=\left\{E\left(x,\left[t_{0}, t\right]\right) * 2 a H(x)\right\}+b x .
$$

By taking the derivative of equation (13) with respect to $x$, one obtains the erosion function

$$
E\left(x,\left[t_{0}, t\right]\right)=\frac{1}{2 a}\left[\frac{\partial U}{\partial x}-b\right]
$$

Equation (14) permits to derive the erosion function from the measured scarp slope distribution across the scarp at time $t$. For scarps in loose fanglomerates that are post the gravity-driven collapse phase, the erosion function obtained from (14) is a good approximation of a Gaussian curve,

$$
E\left(x,\left[t_{0}, t\right]\right)=\frac{1}{\sqrt{2 \pi \sigma^{2}}} e^{-\frac{x^{2}}{2 \sigma^{2}}}
$$

Figure 3 shows two examples of topographic profiles and of the corresponding slope distribution across abandoned alluvial terrace risers in the Xinjiang province, China. The first profile is from the northern Piedmont of the Tien Shan mountains, west of Urumqi [Avouac et al., this issue], and the second from the region of Hotan in southern Tarim (J.P. Avouac and G. Peltzer., Active tectonics in Southern Tarim (Xinjiang, China): Morphologic analysis of terrace risers and cumulative fault scarps, submitted to Journal of Geophysical Research, 1992). In both cases, the scarps cut unconsolidated alluvium with a small proportion of clay and a sparse vegetation cover. In Figure 3, the crosses are measured and continuous lines are best fit synthetic profiles, assuming a Gaussian model of erosion (parameters are given in the figure captions). We noted that the Gaussian model generally holds for scarps formed in
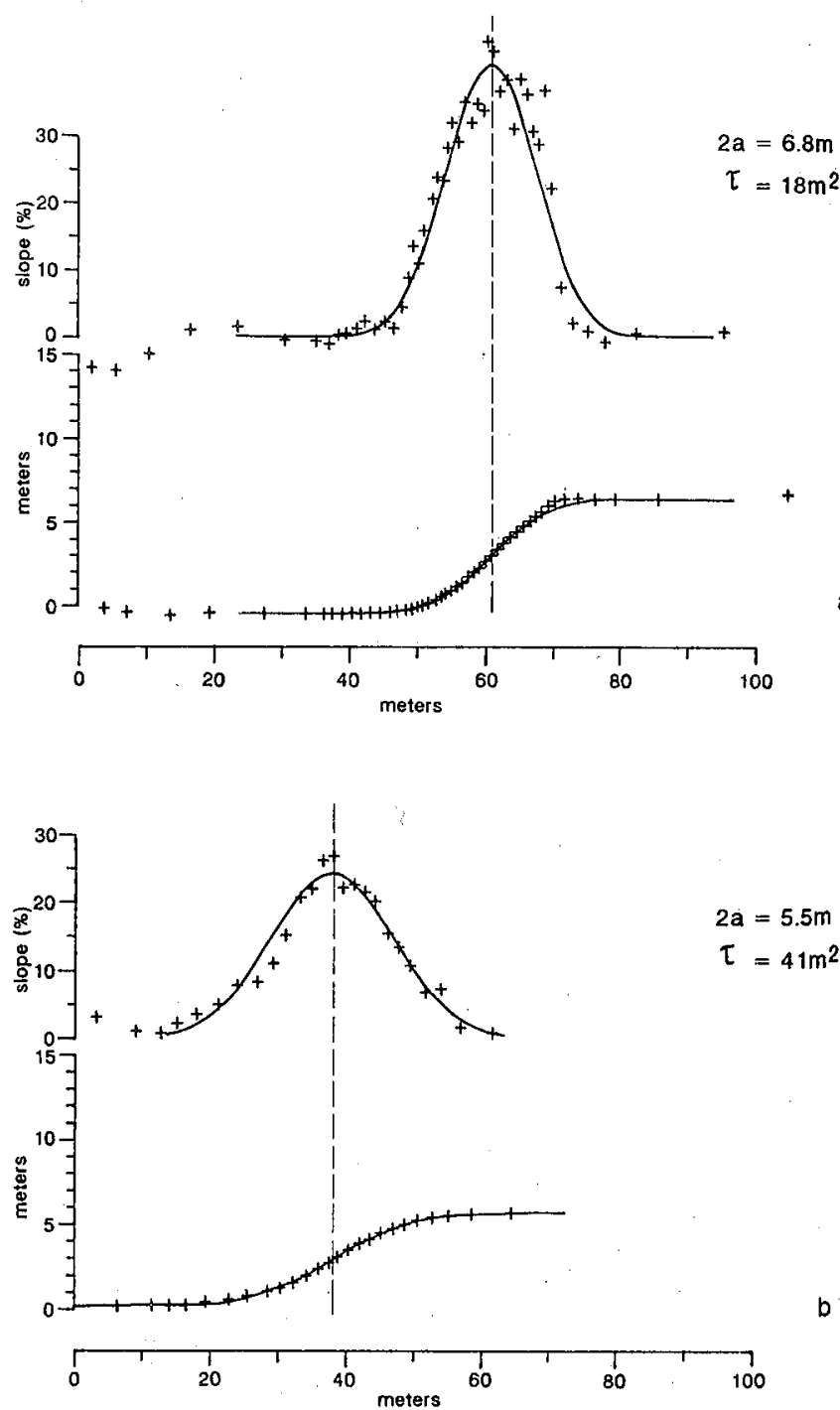

Fig. 3. Example of two profiles across edges of abandoned river terraces. P1 (a) was measured near Jin Gou Heriver, west of Urumqi, in northem Xinjiang [Avouac et al., this issue]. P2 (b) was measured near Hotan in southern Tarim (J.P. Avouac and G. Peltzer, submitted manuscript, 1992). Scarp slope distribution is shown above each profile. "Crosses are measured points. Continuous lines are best fitting synthetic profiles, assuming a Gaussian smoothing model of erosion. 
a single event and less than about ten meters high. High scarps often develop a sharper curvature at the crest than at the base. This effect is visible on the $7 \mathrm{~m}$-high scarp of Figure $3 a$, the crest of which is sharper than that of the synthetic profile. This may be due to concentration of water runoff in small surface rills so that the curvature of the crest between rills and gullies remains sharper than predicted by the Gaussian model. Another explanation might be eolian action: if the vegetation cover is sparse, deflation removes finer elements from the crest of the scarp. This results in the formation of a stone pavement more resistant to erosion processes. By contrast, the profile of Figure $3 b$ displays a smoother basal curvature than that predicted by the Gaussian model. This is also a general pattern that may result from scarp erosion by small surface rills. Such rills tend to deposit small fans at the base of the scarp that sometimes coalesce to form a small bajada. The smoother curvature at base might also be due to trapped eolian sediments (loess) that have been cemented within scarp colluvium.

Despite these problems, for scarps less than $10 \mathrm{~m}$ high, the Gaussian model appears to provide an acceptable approximation to real scarp profiles. In this model the action of erosion is entirely expressed by the erosion function which, since it is a Gaussian curve, is defined by a single parameter, its variance, $\sigma^{2}$. Once the erosion function is known, $\sigma^{2}$ can be considered as a geometric measure of the scarp width, that is, of its state of degradation. The diffusion age, introduced by Andrews and Bucknam [1987] is precisely half the variance of the erosion function as calculated from (14). Since our approach does not rely on the diffusion model, we define the degradation coefficient as $\tau=\sigma^{2} / 2$ with dimension of length squared. This definition refers to the erosion function and does not imply any specific method of inversion for age.

\section{COMPARISON OF THE GAUSSIAN EROSION MODEL WITH THE DIFFUSION MODEL}

The diffusion model is in fact a Gaussian model. Assuming an initial shape $U\left(x, t_{0}\right)$, the solution of (3) can be written

$$
U(x, t)=\frac{1}{\sqrt{\pi \tau}} e^{-\frac{x^{2}}{4 \tau}} * U\left(x, t_{0}\right),
$$

where $\tau=k t$ if $\mathrm{k}$ is constant. If $k$ depends on $t$ (accounting for variation of the rate of erosion), $\tau$ is defined by

$$
\tau=\frac{1}{T} \int_{0}^{T} k(t) t d t
$$

It thus appears that the diffusion model implies a Gaussian erosion function. The only difference between the diffusion model and any other Gaussian model of erosion is the relation between $\tau$ and $t$ (note that Gaussian models all lead to the same set of synthetic profiles). The hypothesis of a constant mass diffusivity $k$ implies that the variance is proportional to numerical age, $\sigma^{2}=2 \mathrm{kt}$, which means a linear calibration of degradation coefficient. Thus, in the diffusion model, the degradation coefficient as defined above is equal to the diffusion age. The good agreement of scarp profiles with synthetic profiles obtained by analytical solutions of the diffusion equation (3) [e.g. Hanks et al., 1984; Nash, 1984] thus corroborates our treatment of erosion as a Gaussian smoothing. However, there is no definitive indication that degradation coefficient is proportional to numerical age, even under constant climatic conditions.

\section{ANALYSIS OF A SCARP PROFILE: METHOD AND UNCERTAINTIES}

The degradation coefficient $\tau$ is a pure geometric parameter which represents the degree of degradation of a scarp with respect to its initial shape, under the assumption of a Gaussian smoothing. Given that the diffusion model is a particular Gaussian model of erosion, we could potentially use any method based on the diffusion model to derive $\tau$ from a scarp profile. Following Nash [1980a] or Hanks et al. [1984], we could either measure $a, b$, and maximum scarp-slope and compute $\tau$ from equation (5) or use the scarp slope offset plot [Hanks et al., 1984], or even compute the second moment of the slope function as*suggested by Andrews and Hanks [1985]. However, since all these methods are sensitive to various sources of error and provide no way to estimate those errors, we prefer the technique of least squares fit of measured profiles to synthetic profiles, adjusting the parameters $a, b, \alpha$, and $\tau$, in order to retrieve an evaluation of the uncertainties in results.

In order to do so, we compute synthetic profiles assuming a planar regional topography, with slope $b$, and a single event with half offset $a$ and initial scarp slope angle $\alpha$. Erosion is modelled by convolution with a Gaussian curve with variance $2 \tau$. The analytical expression of synthetic profiles is given by

$$
\begin{aligned}
& \text { For } \alpha=90^{\circ} \quad U_{\text {syn }}(x, t)=a \operatorname{erf}\left(\frac{x}{2 \sqrt{\tau}}\right) \\
& \text { For } \alpha \neq 90^{\circ} \quad U_{\operatorname{syn}}(x, t)=a\left[\operatorname{erf}\left(\frac{x-a \operatorname{cotg} \alpha}{2 \sqrt{\tau}}\right)\right. \\
& \left.+\operatorname{erf}\left(\frac{x+a \operatorname{cotg} \alpha}{2 \sqrt{\tau}}\right)\right]+a \int_{-a \operatorname{cotg} \alpha}^{a \operatorname{cotg} \alpha} x^{\prime} \operatorname{tg} \alpha e^{\frac{-\left(x-x^{\prime}\right)^{2}}{4 \tau}} d x^{\prime} .
\end{aligned}
$$

For each set of parameters $(b, a, \tau)$ the synthetic profile $U_{\text {syn }}$ is sampled at the data points abcisses $\left(X_{i}\right)_{1<i<N}$ and the standard deviation $\operatorname{SD}(b, a, \tau)$ between sampled synthetic points and measured points is evaluated,

$$
\operatorname{SD}(b, a, \tau)=\left(\frac{1}{N} \sum_{i=1}^{N}\left(U_{i}-U_{\mathrm{syn}}\left(X_{i}\right)\right)^{2}\right)^{\frac{1}{2}}
$$

where $\left(X_{i}, U_{i}\right)$ are measurements.

This function generally passes through a well defined minimum which defines the best fitting synthetic profile. The outcome of the analysis is then a set of three parameters, the regional slope $b$, the half offset, $a$, and the degradation coefficient, $\tau_{\min }$. This procedure contains a bias due to the spacing and density of the measurements, because the standard deviation depends on the sampling, and on the length of the profile. For example, the standard deviation computed for a given synthetic profile can be artificially improved if more points are levelled far from the scarp itself, where the topography is almost planar. A nonuniform sampling gives more weight to the features such as a smooth curvature at the base of the scarp due to deposition of small alluvial fans.

The standard deviation can be modified through the use of a weight function. Each data point $\left(X_{i}, U_{i}\right)$ is given a weight $F_{i}$ so that

$$
\operatorname{SD}(b, a, \tau)=\left[\frac{1}{N} \sum_{i=1}^{N} F_{i}\left(U_{i}-U_{\mathrm{syn}}\left(X_{i}\right)\right)^{2}\right]^{\frac{1}{2}},
$$

where weights are normalized according to

$$
\sum_{i=1}^{N} F_{i}=1
$$


The weight function $F_{i}$ allows separate analysis of crestal and basal curvatures; for example, for the analysis of the crestal curvature, points defining the base are given a zero weight. Moreover, artifacts arising from the contribution of irregularities whose origin is identified (such as small drainage patterns and animal paths) may be reduced. By weighting according to the sampling interval, a nonuniform sampling may be made equivalent to a uniform one using the weight function,

$$
F_{i}=\frac{x_{i-1}-x_{i}}{x_{N}-x_{1}}
$$

Whenever possible, the standard deviation corresponding to a uniform sampling should be used, unless certain field observations indicate that all parts of the profile are not equally significant. However, whatever weight function is used, the standard deviation does not measure objectively the quality of the fit of the synthetic profile to the measured points. A very small standard deviation, relative to the height of the profile, or to the amplitude of the topographic irregularities, does not necessarily mean that the best fitting model is well constrained. We can better evaluate the quality of the constraints provided by the data on the scarp parameters is better evaluated, by computing the standard deviation for a wide range of parameters $(b, a, \tau)$. These parameters are all the better constrained around their optimum values since the standard deviation is more sensitive to small variations of $(b, a, \tau)$.

For illustration, the approach is now applied to the analysis of profile of Figure $3 \mathrm{a}$ and the various parametersare varied independently to show their effect on the results. All measurements were performed with a high precision digital theodolite distance meter (for details on the instrument and levelling procedures, see Peltzer et al., [1988]). Uncertainties are mainly due to the roughness of the topographic surface. We have assumed an angle of repose of $32^{\circ} \pm 4^{\circ}$, which is a standard value for sandy to cobbly loose alluvium. The regional slope is almost horizontal and the scarp is $6.8 \mathrm{~m}$ high. The minimum standard deviation, $\mathrm{SD}_{\min }$, is obtained for the profile shown by a continuous line in Figure $3 a$ and is defined by $b=0 \%, a=3.4 \mathrm{~m}, \tau_{\min }=17.8 \mathrm{~m}^{2}$. For profiles across scarps formed in sandy to cobbly alluvium it appears that the minimum standard deviation is generally of the order of $10 \mathrm{~cm}$. This value may be considered as representative of the typical misfits between synthetic profiles and data. The misfits mostly come from the roughness of the topographic surface and from the inadequation of the Gaussian model or of the idealized initial shape, rather than from measurement errors. The latter factors are the source of systematic misfits (for example, in case of different far-field slopes upslope and downslope of the scarp or of asymmetric basal and crestal curvatures) so that a standard least squares inversion, which assumes normally distributed misfits, would provide unrealistic uncertainties on the model parameters. We define confidence intervals on the model parameters, particularly on the degradation coefficient, $\tau$, which is the parameter of interest, can be defined by considering all the model parameters that yield synthetic profiles that fit the data with standard deviations within about $5 \mathrm{~cm}$ of $\mathrm{SD}_{\min }$ ( $\mathrm{SD}<\mathrm{SD}_{\min }+5 \mathrm{~cm}$ ) (Figure 4). Such a confidence interval on $\tau$ is independant of the distribution and number of measured points. It can be estimated from the plot in Figure 4, where the standard deviation is plotted versus $\tau$. The solid line corresponds to $b$ and $a$ fixed at their optimum values and an initial scarp slope angle of $32^{\circ}$. It is therefore a cross-section of the surface $\operatorname{SD}(b, a, \tau)$, at $a=a_{\text {min }}$ and $b=b_{\min }$. It passes through a well-defined minimum. Ignoring the uncertainties on the initial scarp slope angle, on the of the half

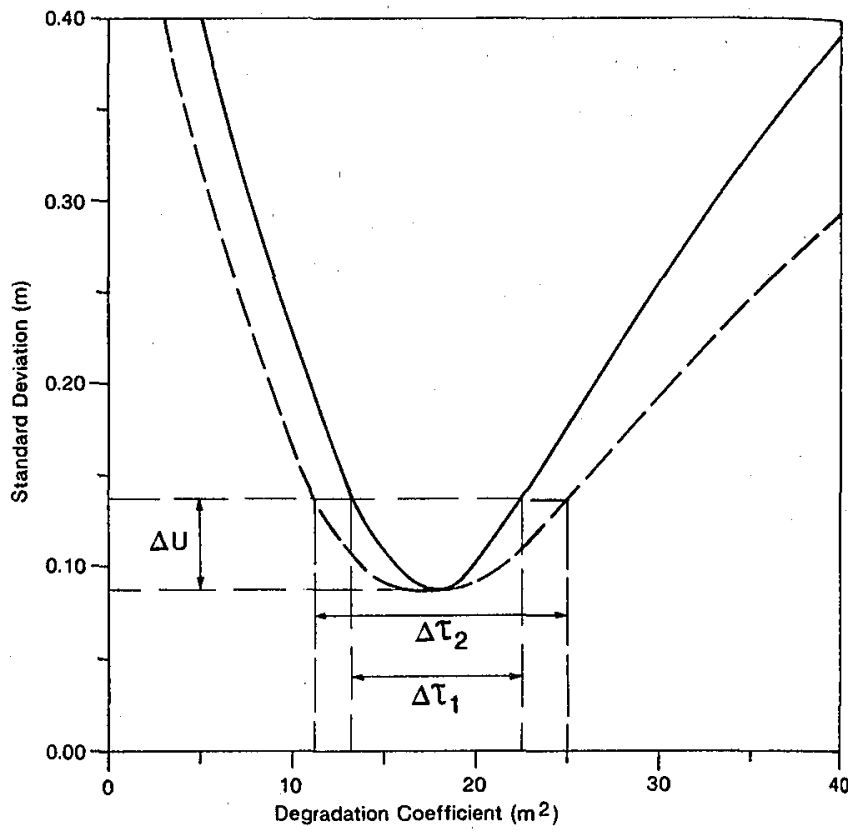

Fig. 4. Mean square value (standard deviation) of vertical misfits between synthetic profiles and levelled points (18), plotted as a function of degradation coefficient $\tau$ for $a$ and $b$ fixed at their optimum values (solid line). Dashed line shows minimum standard deviation obtained by adjusting $a$ and $b$ and by varying the initial scarp slope angle between $28^{\circ}$ and $36^{\circ}$. Confidence intervals on $\tau\left(\Delta \tau_{1}, \Delta \tau_{2}\right)$ the obtained by considering all synthetic profiles that fit data with standard deviation within $5 \mathrm{~cm}(\Delta U)$ of $\mathrm{SD}_{\min }$.

offset and on the regional slope, the following confidence interval on $\tau$ is derived: $13.2 \mathrm{~m}^{2}<\tau_{\min }=18 \mathrm{~m}^{2}<22.5 \mathrm{~m}^{2}$. The dashed line in Figure 4 shows the minimum standard deviation that is obtained for each value of the degradation coefficient by varying simultaneously the regional slope and the half offset, for initial scarp slope angles between $28^{\circ}$ and $36^{\circ}$. The confidence interval on $\tau$ increases to $11.3 \mathrm{~m}^{2}<\tau_{\min }=18 \mathrm{~m}^{2}<25 \mathrm{~m}^{2}$. The profile in this example is long enough so that the regional slope and half offset are tightly constrained. As a result, the optimum degradation coefficient $\tau_{\min }$ is well defined, and its confidence interval is little affected by ignoring uncertainties on $a$ and $b$. Although it is not straightforward to assign a statistical meaning to the confidence interval, it provides an objective and quantitative evaluation of the precision with which the degradation coefficient is determined. The uncertainty on $\tau_{\min }$ might better be assessed by comparing values obtained from different profiles levelled across the same scarp or different similarly oriented scarps otherwise known to be the same age.

Different values of the initial scarp slope angle, that span the whole range of values observed for fanglomerates $\left(20^{\circ}-40^{\circ}\right)$ have been tested (Figure $5 a$ ). An increase in $\alpha$ results in a shift of the curve towards older degradation coefficients, but the minimum value of the standard deviation appears to be unaffected by changes in $\alpha$ (Figure $5 b$ ). Thus, minimization of the standard deviation does not put any constraint on the initial scarp slope angle, which must be determined independently ( $\alpha$ can be easily measured in the field). The error $\Delta \tau_{\min }$ on $\tau_{\min }$ resulting from an error $\Delta \alpha$, does not vary with the age of the scarp. Hence, for old enough scarps the effect of an error in initial scarp slope angle is negligible. In the example of Figure 5 where $\tau / a^{2} \approx 1$, a $5^{\circ}$ uncertainty on $\alpha$ results in a $20 \%$ relative uncertainty on the degradation coefficient. 

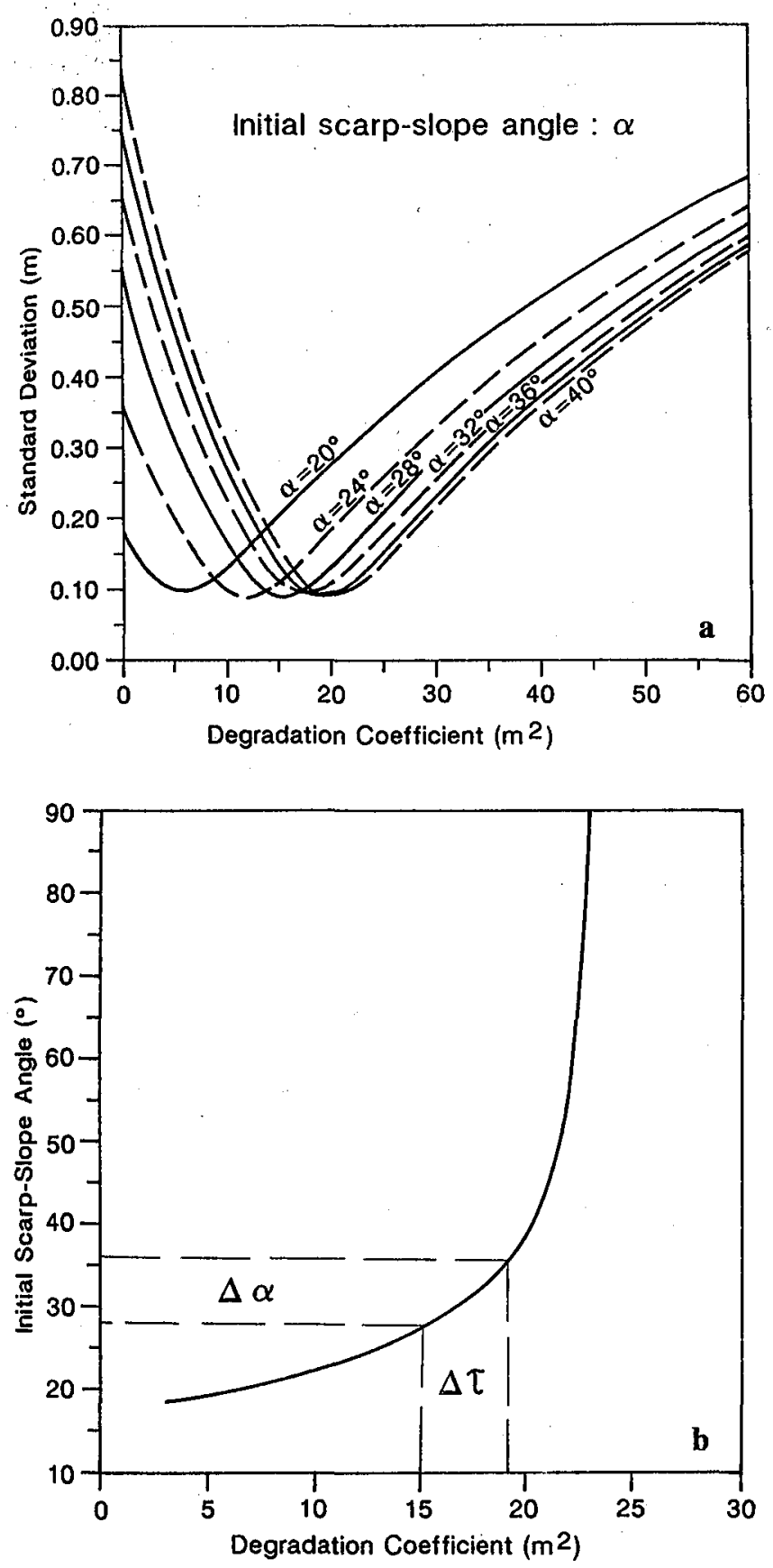

Fig. 5. Sensitivity of degradation coefficient $\tau$ to initial scarp slope angle $\alpha$ (a) Standard deviation plotted versus degradation coefficient assuming different values of initial scarp slope. (b) Plot of optimum degradation coefficient as a function of initial scarp slope.

Hanks and Andrews [1989] pointed out the great sensitivity of the estimation of the degree of degradation of a scarp to small errors in the regional slope. In order to quantify this sensitivity, we have compared results of different analyses for fixed values of the regional slope angle between $-2^{\circ}$ and $2^{\circ}$. Setting the regional slope to a value different from its optimum, $b_{\mathrm{min}}$, shifts the minimum standard deviation away thus defining a degradation coefficient different from that corresponding to $b_{\min }$ (Figure $6 a$ ). Were the regional slope not considered as a free parameter and set to an arbitrary value, an erroneous degradation coefficient might therefore be derived. In the example shown in Figure 6 (which also corresponds to the anaysis of the profile in Figure $3 a$ ), a correct
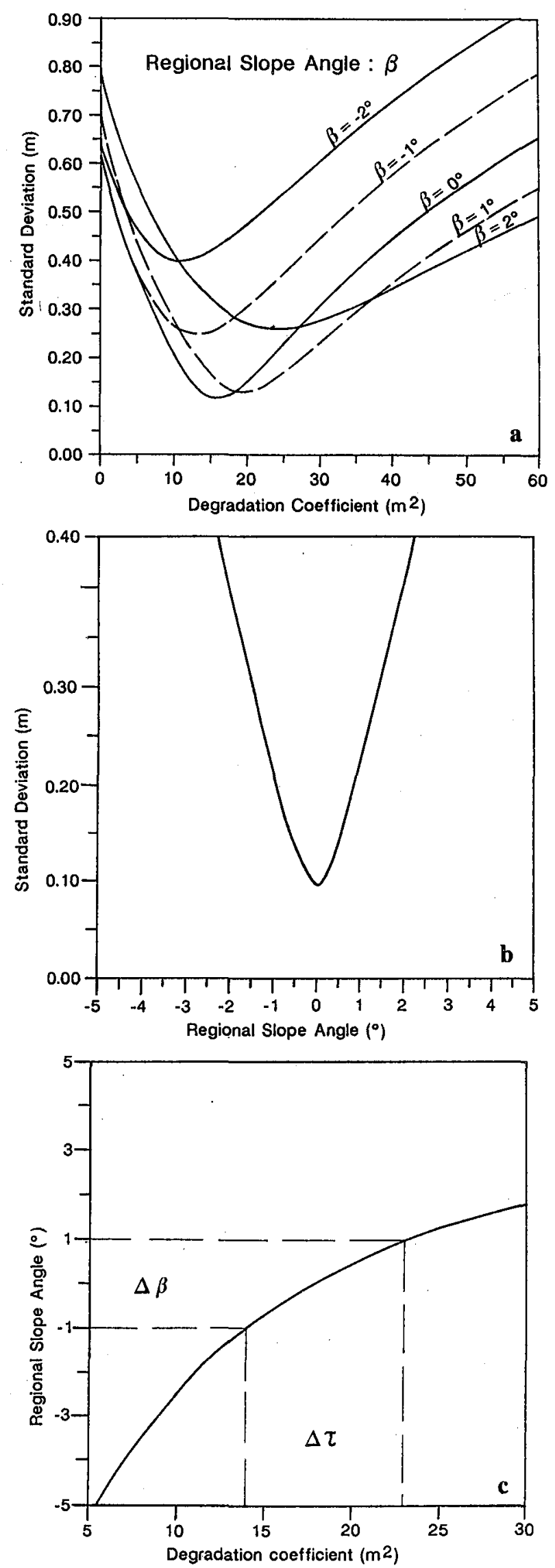

Fig. 6. Sensitivity of degradation coefficient $\tau$ to regional slope angle $\beta$. (a) Standard deviation plotted versus degradation coefficien $t$ for different regional slopes. (b) Plot of minimum standard deviation as a function of regional slope angle. (c) Plot of optimum degradation coefficient versus regional slope angle. 
adjustment of synthetic profiles constrains the regional slope angle $\beta$ $(\beta=\operatorname{arctang} b)$ to be within less than $1^{\circ}$ if the variation of the standard deviation $\mathrm{SD}(b, a, \tau)$ is set not to exceed $5 \mathrm{~cm}$ (Figure 6b). Had the profile been much shorter, equally good standard deviations could have been obtained for different values of the regional slope yielding a poorly constrained optimum degradation coefficient. Figure $6 c$ in which the optimum degradation coefficient is plotted against regional slope, shows that for the profile considered here, a $1^{\circ}$ uncertainty on the regional slope results in a $25 \%$ uncertainty on the degradation coefficient.

Thus it appears that morphologic analysis of a scarp requires long profiles in order to tightly constrain the regional slope and a high density of measured points at the location of the main curvatures since they define the scarp's "width" from which the variance of the Gaussian erosion smoothing hence the degradation coefficient is deduced.

\section{COMPARISON WITH THE REDUCED SCARP SLOPE VERSUS OFFSET PLOT METHOD}

In this section, we compare morphologic dating based on the method presented above with that of Hanks et al. [1984] based on the plot of the reduced scarp slope as a function of scarp half offset. The data set in Table 2 consists of 18 profiles across abandoned terrace risers from the northern piedmont of the Western Kunlun mountains east of the oasis of Hotan (same site as profile in Figure $3 b)$. These terraces lie along valley that are cut at a high angle by normal faults. The repeated entrenchment of the streams in the uplifted footwalls has produced successive terrace deposition and abandonment. The profiles were levelled along different valleys, so that the relative ages of the intermediate terrace risers from one valley to the next is difficult to assess. There is evidence however, that the risers all formed during the Holocene period, the uppermost terrace probably being of early Holocene age (J.P. Avouac and G. Peltzer, submitted manuscript, 1992) After close inspection only six profiles out of 18 were kept for a quantitative morphologic analysis by best fitting to synthetic profiles. Profiles were rejected mostly because of loess deposition at the base of the scarps. All the profiles selected could be fitted with synthetic profiles with minimum standard deviations between 6 and $15 \mathrm{~cm}$. The clustering of the degradation coefficients obtained, with a mean value of
$33 \pm 4 \mathrm{~m}^{2}$ (Table 3), supports the inference that the terrace risers have roughly the same age. In Figure 7 we have plotted the reduced scarp slope of all profiles listed in Table 2, as a function of the half offset. Also shown by dashed lines are the erf functions corresponding to degradation coefficients of $10,20,30,40$ and 50 $\mathrm{m}^{2}$ (Figure 7). If all the terrace edges had formed contemporaneously all points should fit with an erf function (5). The scatter of the eighteen profiles on the reduced scarp slope versus offset plot spans the entire range between the error functions corresponding to degradation coefficient of 10 to $70 \mathrm{~m}^{2}$. Indiscriminantly plotting these profiles thus does not allow the conclusion that the scarps are, even roughly, coeval. If we only consider the six profiles that lend themselves to individual quantitative analysis by best fitting to synthetic profiles (stars in Figure 7), all but one (profile P4) are close to the erf-function corresponding to a degradation coefficient of $30 \mathrm{~m}^{2}$. Even with this outlying profile the shapes of all the scarps are consistent with a degradation coefficient of $30 \pm 10 \mathrm{~m}^{2}$, and thus likely to be coeval within the uncertainty that characterizes satisfactorily constrained degradation coefficients $\left(5\right.$ to $10 \mathrm{~m}^{2}$ ).

\section{Calibration}

Using the method presented here, it has been possible to calibrate the mass diffusivity at a few sites. At the site near Hotan in southwestern Tarim basin, where the climate is arid, for scarps 4-8 $\mathrm{m}$ high, west or SE facing, in unconsolidated fanglomerates, we determined a mass diffusivity of $3.5 \pm 1.2 \mathrm{~m}^{2} / \mathrm{kyr}$ (J.P. Avouac and G. Peltzer, submitted manuscript, 1992). In the northern piedmont of the Dzoungarian Tien Shan, west of Urumqi, where the climate is semiarid, for scarps formed in loose fanglomerates, $5-12 \mathrm{~m}$ high west or east facing, we estimated a mass diffusivity of $5.5 \pm 2$ $\mathrm{m}^{2} / \mathrm{kyr}$ [Avouac et al, this issue]. These first two estimates are based on the simple morphologic assumption that the last large regional alluvial discharge occurred near the onset of the Holocene period, $10 \pm 2 \mathrm{kyr}$ ago. The three values we found for $k$ in three regions of northwestern China are in fair agreement with those obtained for similar scarps under semi arid climates in the western United States [Colman and Watson, 1983; Hanks et al., 1984; Pierce and Colman, 1986; Hanks and Wallace, 1985].

TABLE 2. Profiles Across Early Holocene Terrace Edges

\begin{tabular}{|c|c|c|c|c|c|c|}
\hline Profile & & Offset, $m$ & Scarp Slope, $\%$ & Regional Slope, \% & Scarp Slope \% & Scarp Facing \\
\hline P1 & & 4.35 & 23 & 0 & 23 & $\mathrm{SE}$ \\
\hline $\mathrm{P} 2$ & & 4.6 & 24 & 0 & 24 & $S E$ \\
\hline P3 & . & 5.5 & 27 & 0 & 27 & SE \\
\hline P4 & & 5.3 & 34 & 2.5 & 31.5 & $\mathrm{E}$ \\
\hline P5 & & 7.75 & 36 & 0 & 36 & $\mathrm{~W}$ \\
\hline P6 & & 7.8 & 37 & 0 & 37 & W \\
\hline P7 & & 2.6 & 21 & 0 & 21 & W \\
\hline P8 & & 2.8 & 20 & 0 & 20 & W \\
\hline P9 & & 2.9 & 22 & 0 & 22 & W \\
\hline P10 & & 4.05 & 18.5 & 0 & 18.5 & W \\
\hline $\mathrm{P} 11$ & & 5.5 & 25.5 & 0 & 25.5 & W \\
\hline P12 & & 5.65 & 25.5 & 0 & 25.5 & W \\
\hline P13 & & 6.3 & 34.5 & 0 & 34.5 & W \\
\hline P14 & & 6.7 & 34 & 1 & 33 & W \\
\hline P15 & & 7. & 36 & 0 & 25 & W \\
\hline P17 & & 8.3 & 35 & 1 & 34 & W \\
\hline $\mathrm{P} 18$ & & 10.2 & 36 & 0 & 36 & W \\
\hline
\end{tabular}


TABLE 3. Morphologic Analysis of Terrace Edges

\begin{tabular}{ccccc}
\hline Profile & Offset, $\mathrm{m}$ & Reg. Slope. \% & Std. Dev., cm & Degradation, $\mathrm{m}^{2}$ \\
\hline P1 & 4.35 & 0 & 10.7 & $18<28<38$ \\
P2 & 4.6 & 0 & 4.6 & $23<29<37$ \\
P3 & 5.5 & 0 & 6.0 & $33<41<49$ \\
P4 & 5.3 & 2.5 & 8.9 & $22<32<42$ \\
P5 & 7.75 & 0 & 13 & $28<34<40$ \\
P6 & 7.8 & 0 & 14.5 & $26<33<39$ \\
\hline
\end{tabular}

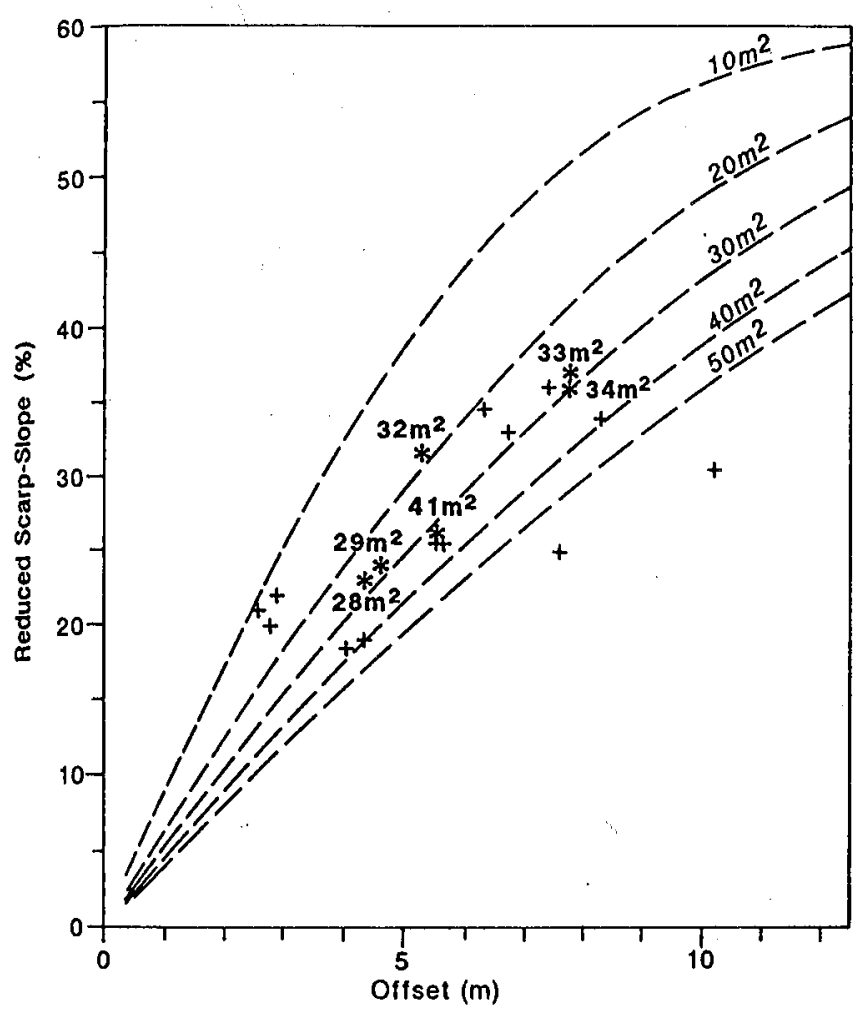

Fig. 7. Reduced scarp slope $(\tan \alpha-b)$ plotted as a function of offset for 18 abandoned terrace risers of early Holocene age [Avouac et al., this issue]. Data are from Table 2. Stars indicate profiles that were analyzed individually by best fitting adjustement to synthetic profiles (parameters and results listed in Table 3). Numbers indicate degradation coefficients obtained from these analyses. Dashed lines are erf functions corresponding to degradation coefficients of $10,20,30,40$, and $50 \mathrm{~m}^{2}$.

\section{CUMULATIVE OR MULTIPLE FAULT SCARPS}

In the previous sections, we have considered scarps formed during a single event on an assumed planar slope. This generally applies to risers seperating alluvial terraces. By contrast, most fault scarps are the result of repeated earthquakes or multiple ruptures and in general the most recent scarp does not cut a region of uniform slope. Theoretically, our method of least squares fitting with synthetic profiles should allow analysis of such compound and multiple scarps. It is easy to compute synthetic profiles resulting from the superposition of several elementary scarps with different degradation coefficients, heights and positions on a planar regional topography. In practice, however, such analyses rarely yield a unique solution, and the quality of the fit is, in general, little improved by performing the analysis assuming one or several events [e.g., Mayer, 1984]. If for example a scarp is analyzed as the result of two ruptures, synthetic profiles are defined by eightr parameters (the regional slope, the height, the position $x$, and degradation coefficient of each event). Unless additional constraints such as the position or offset of the youngest event can be inferred by field observation, there is, in general, no unique solution and equally good fits for a.wide range of solutions may be obtained. We have performed a two-rupture analysis of 10 profiles across a thrust fault scarp near the city of Gaotai (Gansu Province, China) which probably rupured last during the $M \sim 7.5,180$ A.D. Luo To Chen earthquake [Tapponnier et al. , 1990] and for which field evidence showed that the total offset resulted from two earthquakes. The profiles also revealed along strike changes of the scarp geometry which could not be accounted for by a single-event analysis. For all profiles, the two-events analysis singled out a wellconstrained recent event $\left(a \approx 0.8 \mathrm{~m}, \tau=6 \pm 3 \mathrm{~m}^{2}\right.$; Table 2 of Tapponnier et al. [1990]), most likely the trace of the 180 A.D. earthquake. The identification of the the scarp of that old, wellrecorded earthquake permitted calibration of the mass diffusivity constant in that part of the Gansu province $\left(k=3.3 \pm 1.7 \mathrm{~m}^{2} / \mathrm{kyr}\right)$, a value close to that determined in the southwestern Tarim.

\section{CONCLUSION}

Morphologic dating of scarp-like landforms requires a procedure to estimate the degree of degradation of a scarp with reference to a simple model of scarp smoothing by erosion, and calibration. We propose to estimate the degree of degradation of a scarp by measuring long profiles across the same scarp, inspecting all profiles individually (in particular their scarp-slope distribution plots), and least-squares fitting the selected profiles to synthetic profiles generated with a Gaussian smoothing model of erosion. This approach yields a degradation coefficient $\tau$ with a confidence interval that asseses quantitatively the measurement uncertainties and the effect of ill-constrained parameters. This method differs from previous methods based on the diffusion model of scarp degradation in the following ways. First, it contains a test of feasability. A profile whose slope distribution plot is too far from synthetic slope profiles will be rejected from the data set unless the misfit can explained and corrected for. Second, an estimate of the state of degradation of a profile from best fitting adjustement to synthetic profiles allows quantification of uncertainties. The uncertainty on the regional slope appears to be the main source of uncertainty in the determination of the degradation coefficient so that long profiles are required for well constrained analyses. Another source of error, that cannot be adressed in the two-dimensional approach presented here, results from the fact that the shape of real scarps are often modified by three dimensional morphological processes (rills or gullies, small fans at base, loess deposits, lateral stream incision, etc.). It is thus important to eliminate such effects by careful site selection and by levelling several parallel profiles across the same scarp. The consistency between independent analyses of different profiles across the same scarp provides an ultimate test that the modelling is valid. We suspect that with systematic application of this technique, as well as with screening of earlier data, and in spite of the problems so far encountered, morphologic analysis and dating can be a cheap rapid and efficient tool for neotectonics studies, particularly for scarps younger that $\approx 20 \mathrm{ka}$ formed in loosly consolidated alluvium.

Acknowledgments. I am grateful to Paul Tapponnier, Gilles Peltzer, and Yves Gaudemer who critically read the manuscript, and I thank Bertrand Meyer and Rolando Armijo for numerous discussions. Geoff King, Ross Stein and Albert Tarantola also provided helpful comments. This is IPGP contribution 1244. 


\section{REFERENCES}

Andrews, D.J., and R.C. Bucknam, Fitting degradation of shoreline scarps by a non linear diffusion model, J. Geophys. Res., $92,12,857-12,867$, 1987.

Andrews, D.J. and T. C. Hanks, Scarp degraded by linear diffusion: Inverse problem for age, J. Geophys. Res., 90, 10,193-10,208, 1985.

Avouac, J.P., P. Tapponnier, M. Bai, H You, G. Wang, Active faulting and folding along the northern Tien Shan and Late Cenozoic rotation of Tarim relative to Dzungaria and Kazakhstan, J. Geophys. Res., this issue.

Avouac, J.P. and G. Peltzer, Active tectonics in Southern Tarim (Xinjiang, China): morphologic analysis of terrace risers and cumulative normal fault scarps, submitted to J.G.R.

Bucknam, R.C., and R.E. Anderson, Estimation of fault-scarp ages from a scarp-height-slope-angle relationship, Geology, 7, 11-14, 1979.

Carson , M.A., and M.J. Kirkby, Hillstope, Form and Process, 475 pp., Cambridge, 1972.

Colman, S.M., and K. Watson, Ages estimated from diffusion-equation model for scarp degradation, Science, 221, 263-265, 1983.

Gossmann, H., Slope modelling with changing boundary conditions-effects of climate and lithology, Z. Geomorpol.., 25, 72-88, 1976.

Hanks T.C., and J. Andrews, Effect of far-field slope on morphologic dating of scarplike landforms, J. Geophys. Res., 94, 565-573, 1989.

Hanks, T.C., and D.P. Schwartz, Morphologic dating of the pre-1983 fault scarp on the Lost River fault at Doublepring Pass Road, Custer County, Idaho, Bull. Seismol. Soc. Am., 77, 837-846, 1987.

Hanks, T.C. and R.E. Wallace, Morphological analysis of the lake Lahontan shoreline and beachfront fault scarps, Persching County, Nevada, Bull. Seismol. Soc. Am., 75, 835-846, 1985.

Hanks, T.C.,R.C. Bucknam, K.R. Lajoie, and R.E. Wallace, Modification of wave-cut and faulting-controlled landforms, J. Geophys.Res., 89, 5771$5790,1984$.

Mayer, L., Dating quaternary fault scarps formed in alluvium using morphologic parameters, Quat. Res., 22, 300-313, 1984.
Nash, D.B., Morphologic dating of degraded normal fault scarps, $J$. Geol, $88,353-360,1980 a$.

Nash, D.B., Fault: A FORTRAN program for modeling the degradation of active normal fault scarp, Comput. and Geosci., 7, 249-266, 1980 b.

Nash, D.B., Morphologic dating of fluvial terrace scarps and fault scarps near West Yellowstone, Montana, Geol. Soc. Am. Bull , 95, 1413-1424, 1984.

Peltzer, G., P. Tapponnier, Y. Gaudemer, B. Meyer, S. Guo, K. Yin, Z. Chen and H. Dai, Offsets of late quatemary morphology, rate of slip, and recurrence of large earthquakes on the Chang Ma Fault, $J$, Geophys. Res., 93, 7793-7812, 1988.

Pierce, K.L., and S.M. Colman, Effect of height and orientation (microclimate) on geomorphic degradation rates and processes, late glacial terrace scarps in central Idaho, Geol. Soc. Am. Bull., 97, 869. $885,1986$.

Tapponnier, P., B. Meyer, J.P. Avouac, G. Peltzer, Y. Gaudemer, G, Shunmin, X. Hongfa, Y. Kelun, C. Zhitai, C. Shuahua, and D. Huagang, Active thrusting and folding in the Qilian Shan, and decoupling between upper crust and mantle in northeastern Tibet, Earth Planet. Sci. Lett., 97, 382-403, 1990.

Wallace, R.E., Profiles and ages of young fault scarps, north-central Nevada, Geol. Soc. Am. Bull, 88, 1267-1281, 1977.

J.P. Avouac, LDG/CEA, B.P. 12, 91680, Bruyères-le-Châtel, France.

(Received October 29, 1991; revised July 29, 1992;

accepted August 28, 1992.) 